\section{Gait speed and pedestrian crossings in COPD}

\section{ABSTRACT}

The assumed minimum walking speed at pedestrian crossings is $1.2 \mathrm{~m} / \mathrm{s}$. In this prospective cohort study, usual walking speed was measured over a $4 \mathrm{~m}$ course in 926 community-dwelling, ambulatory patients with stable COPD. Mean (SD) walking speed was $0.91(0.24) \mathrm{m} / \mathrm{s}$ with only $10.7 \%$ walking at a speed equal or greater than $1.2 \mathrm{~m} / \mathrm{s}$. In order for $95 \%$ of this cohort to safely negotiate a pedestrian cross, traffic lights would have to assume a minimum walking speed of $0.50 \mathrm{~m} / \mathrm{s}$ (2.4 times longer than current times). The current assumed normal walking speed for pedestrian crossings is inappropriate for patients with COPD.

The studies were registered on clinicaltrials. gov and these data relate to the pre-results stage: NCT01649193, NCT01515709 and NCT01507415.

\section{INTRODUCTION}

In many countries, including the USA, ${ }^{1}$ Canada, ${ }^{2}$ Ireland, ${ }^{3}$ South Africa ${ }^{4}$ and the $\mathrm{UK}^{5}$ pedestrian crossings assume a minimum walking speed of $1.2 \mathrm{~m} / \mathrm{s}$ equivalent to $4 \mathrm{ft} / \mathrm{s}^{5}$ Recent epidemiological studies have shown a significant proportion of older adults in the UK and Ireland walk slower than $1.2 \mathrm{~m} / \mathrm{s}$, while more than half of all pedestrians killed on the road are over 65 years of age despite this age group representing $<20 \%$ of the population. ${ }^{6}$ With an ageing population, there are concerns that insufficient time to negotiate pedestrian crossings safely will become an increasing public health problem. ${ }^{6}$

Patients with COPD, in whom exertionrelated breathlessness and exercise intolerance are common, may be particularly vulnerable. The aim of our study was to assess normal walking speed in a cohort of community-dwelling, ambulatory patients with stable COPD. We hypothesised that only a small minority of patients with stable COPD would have walking speeds greater than $1.2 \mathrm{~m} / \mathrm{s}$.

\section{METHODS}

This was a prospective cohort study and data were collected between November 2009 and October 2013 in patients recruited from community-based and hospital-based respiratory and pulmonary rehabilitation clinics at Harefield Hospital, UK. Inclusion criteria included a diagnosis of COPD according to Global Initiative for Chronic Obstructive Lung Disease guidelines, ambulatory (defined as leaving the house at least once a week and able to walk $10 \mathrm{~m}$ independently) and stable disease (no change in medications in previous 6 weeks). All participants provided informed consent and the London Camberwell-St. Giles (11/LO/1780) and West London (11/H0707/2) Research Ethics Committees approved the study. Usual walking speed was measured as the $4 \mathrm{~m}$ gait speed (4MGS) with a standing start as previously described. ${ }^{7-10}$ Other measurements recorded included $\mathrm{FEV}_{1}$, the Medical Research Council dyspnoea scale (MRC) and the incremental shuttle walk test (ISW).

\section{RESULTS}

We asked 973 patients to consider participating in the study: 38 declined to participate $(n=15$ : family commitments, $n=10$ : not interested in research, $\mathrm{n}=9$ : no reason provided, $n=4$ : miscellaneous reasons) and 9 did not meet the study inclusion criteria $(n=6$ : recent change in medication, $\mathrm{n}=3$ : unable to walk $10 \mathrm{~m}$ ). Data were available in 926 patients (548 men; 378 women). Baseline characteristics were expressed as mean (SD): age 69 (10) years, $\mathrm{FEV}_{1} 49.8$ (20.9) \%, MRC 3.3 (1.1), ISW $223(150) \mathrm{m}$ and 4MGS $0.91(0.24) \mathrm{m} / \mathrm{s}$. Fifty-five per cent, $32 \%$ and $14 \%$ had concomitant hypertension/cardiovascular disease, obesity and osteoarthritis, respectively, while 5\% used ambulatory oxygen. 4MGS was weakly associated with age $(r=$ -0.21), $\mathrm{FEV}_{1}$ \%predicted $(\mathrm{r}=0.11)$, moderately with respiratory disability (MRC: $\mathrm{r}=-0.51$ ) and strongly with exercise capacity (ISW: $\mathrm{r}=0.78$ ); all $\mathrm{p}<0.001$. Frequency distribution of $4 \mathrm{MGS}$ for the cohort is shown in figure 1 , demonstrating that only $10.7 \%$ had a walking speed equal to or greater than $1.2 \mathrm{~m} / \mathrm{s}$.

\section{DISCUSSION}

Our cohort of ambulatory patients with stable COPD had significantly slower walking speeds than previously reported in age-matched healthy people (mean (95\% CI)), males: 1.4 (1.27 to 1.41$) \mathrm{m} / \mathrm{s}$; females: 1.24 (1.18 to 1.30$) \mathrm{m} / \mathrm{s}),{ }^{11}$ but were faster than those at discharge following a hospitalised acute exacerbation of COPD (mean (SD) $0.61 \quad(0.26) \quad \mathrm{m} / \mathrm{s}){ }^{9}$ Slow walking speed was associated with increasing respiratory disability (MRC) and decreased exercise tolerance (ISW). ${ }^{8}$

UK pedestrian crossing timings assume a minimum walking speed of $1.2 \mathrm{~m} / \mathrm{s}$, yet only $10.7 \%$ of our cohort with stable COPD would have sufficient time to walk across a pedestrian crossing safely. In order to accommodate at least $95 \%$ of our cohort, pedestrian crossings would have to assume a minimum walking speed of $0.50 \mathrm{~m} / \mathrm{s}$, resulting in traffic lights having to stay red 2.4 times longer than current times.

A limitation of the study is that gait speed measurements were carried out indoors, on a flat undisturbed $4 \mathrm{~m}$ walking course in a controlled outpatient setting. This may not reflect real-life conditions at pedestrian crossings such as the weather, road and pavement surface quality, varying walk distances, interactions with other pedestrians and driver behaviour. Therefore, it is possible that our gait-speed measurement actually overestimates real-life walking speed at a pedestrian crossing. In contrast, it could also be argued that with the visual or auditory feedback at a pedestrian crossing, patients with COPD and a degree of functional reserve may adopt a walking speed closer to maximum, rather than usual, gait speed.

Further work is required to assess whether the discrepancy between pedestrian crossing times and patients' walking

Figure 1 Frequency histogram of $4 \mathrm{~m}$ gait speed (4MGS) in a cohort of 926 ambulatory patients with stable COPD. Dotted line indicates the minimum walking speed assumed by pedestrian crossings $(1.2 \mathrm{~m} / \mathrm{s})$. 
speed may influence engagement in physical activity, a significant modifiable prognostic risk factor. ${ }^{12}$ Patients with COPD have limitations in every aspect of daily life and inability to negotiate the local environment may deter patients from engaging in physical or social activities outside their home. Indirect evidence to support this includes the previously described association between slow gait speed and reduced objectively measured physical activity levels in outpatients with COPD. ${ }^{13}$ Our data would support an evaluation of solutions to improve pedestrian safety particularly in people with COPD, including extended pushbuttons, countdown timers and pedestrian infrared detectors as well as the use of technology to allow variable pedestrian crossing times based on local factors such as weather and traffic.

In summary, approximately $90 \%$ of stable outpatients with COPD have a usual walking speed below the minimum walking speed assumed by pedestrian crossings. Currently, assumed normal walking speed for pedestrian crossings is inappropriate for patients with COPD.

\section{Claire M Nolan, ${ }^{1,2}$ Samantha S C Kon, ${ }^{1,2,3}$ Suhani Patel, ${ }^{1,2}$ Sarah E Jones, ${ }^{1,2}$ Ruth E Barker, ${ }^{1,2}$ Michael I Polkey, ${ }^{2}$ Matthew Maddocks, ${ }^{4}$ William D-C Man ${ }^{1,2}$}

${ }^{1}$ Harefield Pulmonary Rehabilitation and Muscle Research Laboratory, Harefield Hospital, Harefield, UK ${ }^{2} \mathrm{NIHR}$ Respiratory Biomedical Research Unit, Royal Brompton \& Harefield NHS Foundation Trust and Imperial College, Harefield, UK

${ }^{3}$ Department of Respiratory Medicine, The Hillingdon Hospitals NHS Foundation Trust, London, UK ${ }^{4}$ King's College London, Cicely Saunders Institute, London, UK

Correspondence to Claire Nolan, NIHR Doctoral Fellow, Pulmonary Rehabilitation, Department of
Respiratory Medicine, Harefield Hospital, Harefield, Middlesex UB9 6JH, UK; c.nolan@rbht.nhs.uk

Acknowledgements The authors thank the patients for their participation in this study.

Contributors CNM and SSCK contributed equally to this study. WD-CM, SSCK, MM: substantial contributions to the conception and design of the study; CMN, SSCK, SP, SEJ, REB: substantial contribution to the acquisition of data; CMN, SSCK, MIP, MM, WM: analysis and interpretation of the data; CMN, SSCK, MIP, MM, WD-CM: first draft of the manuscript; All authors: revision of the manuscript critically for important intellectual content, approval of the final manuscript; CMN, SSCK, WD-CM: accountability for all aspects of the work.

Funding This work was supported by a Medical Research Council (UK) New Investigator Research Grant (G1002113/98576) awarded to WD-CM.

Competing interests This work was supported by a Medical Research Council (UK) New Investigator Research Grant (G1002113/98576) awarded to WD-CM, who was also supported by the National Institute for Health Research (NIHR) Collaboration for Leadership in Applied Health Research and Care (CLAHRC) for Northwest London. CMN and SEJ are supported by NIHR Doctoral Research Fellowships. MM is supported by NIHR CLAHRC for South London. The views expressed in this publication are those of the authors and not necessarily those of the Medical Research Council, the NHS, the National Institute for Health Research or the Department of Health.

Ethics approval West London and London Dulwich Research Ethics Committees.

Provenance and peer review Not commissioned; externally peer reviewed.

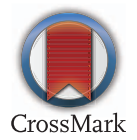

To cite Nolan CM, Kon SSC, Patel S, et al. Thorax Thorax 2018;73:191-192.

Received 21 February 2017

Revised 4 April 2017

Accepted 17 April 2017

Published Online First 5 May 2017
Thorax 2018;73:191-192.

doi:10.1136/thoraxjnl-2017-210173

\section{REFERENCES}

1 Administration FH. Manual on Uniform Traffic Control Devices for Streets and Highways. Washington DC: Transportation UDo, 1978.

2 Ontario Go. Ontario traffic manual—Book 12etraffic signals 2001. http://www.directtraffic.ca/wp-content/ uploads/2014/02/Book-121.pdf (accessed 28 Mar 2017).

3 Transport Do. Traffic signals manual 2010. http:// www.dttas.ie/sites/default/files/publications/roads/ english/traffic-signs-manual-2010/traffic-signsmanual-2010-chapter-1-introduction-and-signlocation.pdf (accessed 28 Mar 2017).

4 Amosun SL, Burgess T, Groeneveldt L, et al. Are elderly pedestrians allowed enough time at pedestrian crossings in Cape Town, South Africa? Physiother Theory Pract 2007;23:325-32.

5 Asher L, Aresu M, Falaschetti E, et al. Most older pedestrians are unable to cross the road in time: a cross-sectional study. Age Ageing 2012;41:690-4.

6 Tournier I, Dommes A, Cavallo V. Review of safety and mobility issues among older pedestrians. Accid Anal Prev 2016;91:24-35.

7 Kon SS, Canavan JL, Nolan CM, et al. The 4-metre gait speed in COPD: responsiveness and minimal clinically important difference. Eur Respir J 2014;43: 1298-305.

8 Kon SS, Patel MS, Canavan JL, et al. Reliability and validity of 4-metre gait speed in COPD. Eur Respir J 2013;42:333-40.

9 Kon SS, Jones SE, Schofield SJ, et al. Gait speed and readmission following hospitalisation for acute exacerbations of COPD: a prospective study. Thorax 2015;70:1131-7.

10 Maddocks M, Kon SS, Canavan JL, et al. Physical frailty and pulmonary rehabilitation in COPD: a prospective cohort study. Thorax 2016;71:988-95.

11 Bohannon RW, Williams Andrews A. Normal walking speed: a descriptive meta-analysis. Physiotherapy 2011;97:182-9.

12 Waschki B, Kirsten A, Holz O, et al. Physical activity is the strongest predictor of all-cause mortality in patients with COPD: a prospective cohort study. Chest Journal 2011;140:331-42.

13 DePew ZS, Karpman C, Novotny PJ, et al. Correlations between gait speed, 6 -minute walk distance, physical activity, and self-efficacy in patients with severe chronic lung disease. Respir Care 2013;58:2113-9. 